\title{
PRODUÇÃO E REPRODUÇÃO SOCIAL ENTRE BENEFICIÁRIOS DO PRONAF B NO SEMIÁRIDO BRASILEIRO ${ }^{1}$
}

\author{
PRODUCTION AND SOCIAL REPRODUCTION AMONG \\ BENEFICIARIES OF PRONAF B IN THE BRAZILIAN SEMI-ARID
}

\section{PRODUCCIÓN Y REPRODUCCIÓN SOCIAL ENTRE BENEFICIARIOS DEL PRONAF B EN EL SEMIÁRIDO BRASILEÑO}

\author{
Maria Odete Alves ${ }^{2}$ \\ ORCID: https://orcid.org/0000-0002-8775-2226 \\ Maria de Fátima Vidal ${ }^{3}$ \\ ORCID: https://orcid.org/0000-0003-3848-6109 \\ Iracy Soares Ribeiro Maciel ${ }^{4}$ \\ ORCID: https://orcid.org/0000-0001-9562-506X \\ Alysson Inacio de Oliveira ${ }^{5}$ \\ ORCID: https://orcid.org/0000-0002-1723-1716
}

Submetido: 25/06/2020 / Aceito: 13/08/2020.

\begin{abstract}
Resumo
Este artigo estudou os beneficiários do Pronaf B no Semiárido brasileiro. O objetivo foi conhecer as condições materiais de produção e as estratégias adotadas para a reprodução social do grupo familiar. Partiu-se do pressuposto de que existe uma diversidade significativa de modos e bases materiais de produção e conhecimento entre agricultores. As estratégias de produção e reprodução que elaboram é função dessas bases e de sua interação com os meios socioeconômico e agroecológico. Utilizaram-se dados de uma base de pesquisa de campo do BNB realizada entre clientes do Pronaf em 2012, com o uso de questionários semiestruturados. Adotou-se o recorte para Pronaf B no Semiárido, que contempla 445 questionários dos 3.000 aplicados. Os resultados mostram que a maioria dos entrevistados

\footnotetext{
${ }^{1}$ Uma versão ampliada deste artigo, sob o título "Beneficiários do Pronaf B no Semiárido brasileiro: perfil socioeconômico, condições materiais de produção e estratégias reprodução", foi publicada no livro "Avaliação de Políticas Públicas no Brasil: uma análise do semiárido", editado pelo Ipea em 2019.

${ }^{2}$ Engenheira agrônoma, doutora em desenvolvimento sustentável e pesquisadora do Escritório Técnico de Estudos Econômicos do Nordeste (Etene)/Banco do Nordeste do Brasil (BNB). Fortaleza, Ceará, Brasil. Email: moalves1@gmail.com.

${ }^{3}$ Engenheira agrônoma, mestra em economia rural e pesquisadora do Escritório Técnico de Estudos Econômicos do Nordeste (Etene)/Banco do Nordeste do Brasil (BNB). Fortaleza, Ceará, Brasil. E-mail: fatimavidal@bnb.gov.br.

${ }^{4}$ Pedagoga, mestra em avaliação de políticas públicas e pesquisadora do Escritório Técnico de Estudos Econômicos do Nordeste (Etene)/Banco do Nordeste do Brasil (BNB). Fortaleza, Ceará, Brasil. E-mail: iracysrm@bnb.gov.br.

${ }^{5}$ Graduando em ciências econômicas, bolsista de nível superior do Escritório Técnico de Estudos Econômicos do Nordeste (Etene)/Banco do Nordeste do Brasil (BNB). Fortaleza, Ceará, Brasil. E-mail: alyssoninacio@ hotmail.com.
} 
tem boa capacidade de leitura, dispõe de moradias próprias e acesso a redes de abastecimento de água e energia elétrica. Mas a indisponibilidade de terras e de outros capitais físicos, associada às condições agroecológicas do semiárido, inviabilizam a produção em maior escala que, por sua vez, dificulta ou torna inadequado o uso de determinados equipamentos e implementos agrícolas, além de algumas práticas ou tecnologias. Para superar as limitações, elaboram estratégias de uso de terras em parceria, arrendamento e cessão, diversificação da produção, consórcio entre culturas, pluriatividade dentro e fora da unidade familiar, acesso ao crédito e prioridade a mercados de proximidade.

Palavras-chave: Agricultura familiar. Pronaf B. Semiárido. Meios de produção. Diferenciação.

\begin{abstract}
This paper studied the beneficiaries of Pronaf $\mathrm{B}$ in the Brazilian semiarid region. The objective was to know the material conditions of production and the strategies adopted for the social reproduction of the family group. It was assumed that there is a significant diversity of modes and material bases of production and knowledge among farmers. The production and reproduction strategies they elaborate are a function of these bases and their interaction with the socioeconomic and agroecological environments. Data from a BNB field research base carried out among Pronaf clients in 2012 were used, using semi-structured questionnaires. The Pronaf B cut in the Semi-Arid was adopted, which includes 445 questionnaires of the 3,000 applied. The results show that the most of interviewees have good reading skills, have their own homes and access to water and electricity supply networks. But the unavailability of land and other physical capital, associated with agroecological conditions in the semi-arid region, make large-scale production unfeasible, which in turn makes it difficult or inappropriate to use certain agricultural equipment and implements, in addition to some practices or technologies. To overcome the limitations, they develop strategies for the use of land in partnership, leasing and assignment, diversification of production, consortium between cultures, pluriactivity within and outside the family unit, access to credit and priority to proximity markets.
\end{abstract}

Keywords: Family farming. Pronaf B. Semi-arid. Production means. Differentiation.

\title{
Resumen
}

Este artículo estudió a los beneficiarios de Pronaf B en la región semiárida brasileña. El objetivo fue conocer las condiciones materiales de producción y las estrategias adoptadas para la reproducción social del grupo familiar. Se asumió que existe una gran diversidad de modos y bases materiales de producción y conocimiento entre los agricultores. Las estrategias de producción y reproducción que elaboran son una función de estas bases y su interacción con los entornos socioeconómicos y agroecológicos. Se utilizaron datos de una base de investigación de campo de BNB realizada entre clientes de Pronaf en 2012, mediante cuestionarios semiestructurados. Se adoptó el corte Pronaf B en el semiárido, que incluye 445 cuestionarios de los 3.000 aplicados. Los resultados muestran que la mayoría de los encuestados tienen buenas habilidades de lectura, tienen sus propios hogares y acceso a redes de suministro de agua y electricidad. Sin embargo, la falta de disponibilidad de tierra y otro capital físico, asociado con condiciones agroecológicas en la región semiárida, hace inviable la producción a mayor escala, lo que a su vez dificulta o hace inadecuado el uso de ciertos equipos e implementos agrícolas, además de algunas prácticas o tecnologías. Para superar las 
limitaciones, desarrollan estrategias de el uso de la tierra en sociedad, arrendamiento y cesión, diversificación productiva, consorcio entre culturas, pluriactividad dentro y fuera de la unidad familiar, acceso al crédito y prioridad a los mercados de proximidad.

Palabras clave: Agricultura familiar. Pronaf B. Semiárido. Medios de producción. Diferenciación

\section{INTRODUÇÃO}

O semiárido brasileiro abrange parte de cada um dos nove estados nordestinos e de Minas Gerais, totalizando 1.262 municípios, conforme delimitação atual (BRASIL. MIN, 2018). Com uma população de cerca de 26,2 milhões de habitantes, é a mais povoada entre as zonas áridas e semiáridas do planeta (IBGE, 2019). Seu ecossistema é naturalmente frágil e apresenta elevada vulnerabilidade econômica e social. Encontra-se no bioma Caatinga, cujas particularidades incluem a variabilidade espacial e temporal do regime de chuvas (ALVES, 2012). Essa variabilidade, associada ao baixo volume de precipitação anual (entre $268 \mathrm{~mm}$ e $800 \mathrm{~mm}$ ), é responsável por um desvio superior a 50\% em relação à média anual (GAMA DA SILVA et al., 2010). Tal característica, ligada à elevada insolação e ao calor intenso durante a maior parte do ano, reflete-se na deficiência hídrica, nas características edáficas e na paisagem dominante no semiárido. Além disso, predominam solos com baixa fertilidade, rasos, com embasamento cristalino que dificultam infiltração, retenção e drenagem de água e, por isso, provocam escoamentos superficiais que facilitam processos erosivos (GAMA DA SILVA et al., 2010).

O território acima descrito abriga os agricultores analisados neste trabalho que, além disso, são beneficiários do Programa Nacional de Fortalecimento da Agricultura Familiar (Pronaf) e se enquadram no Grupo B (Pronaf B), linha específica do Programa destinada aos agricultores mais pobres, desprovidos de capital, terra e trabalho, portanto, com baixa capacidade produtiva.

O enquadramento da agricultura familiar para concessão de créditos do Pronaf é definido pela Lei $n^{\circ}$ 11.326/2006 (Lei da Agricultura Familiar), segundo a qual, o chefe do estabelecimento familiar deve, simultaneamente: exercer a direção dos trabalhos, em conjunto com a família; usar mão de obra predominantemente familiar; explorar área de no máximo quatro módulos fiscais; ter renda familiar originada predominantemente de atividades vinculadas ao próprio estabelecimento. Essa lei fortaleceu o Pronaf e contribuiu para a organização dos agricultores enquanto segmento social, principalmente no que 
concerne às reivindicações de apoios e políticas específicas. Por outro lado, adota conceito que abriga uma diversidade significativa de atores no tocante ao modo de vida e às condições materiais de produção e reprodução. Tal diversidade é consequência de uma diferenciação promovida, em parte, pelo processo de desenvolvimento capitalista, ao determinar condições objetivas de produção desiguais, porque se estabelecem de acordo com o que é efetivamente dado em termos de condições materiais e conceituais de produção, em integração com o meio agroecológico e socioeconômico (ALVES, 2005).

Considerando-se os requisitos definidos na Lei $\mathrm{n}^{\circ} 11.326 / 2006$, de acordo com IBGE $(2006)^{6}, 59,2 \%$ dos estabelecimentos familiares brasileiros estão agrupados na categoria Pronaf B. Desses, 46,4\% (1.246.475) localizam-se no semiárido, correspondendo a 71,8\% dos estabelecimentos nordestinos enquadráveis no Pronaf B e a 65,7\% dos familiares do próprio semiárido. Tais estabelecimentos são submetidos a condições agroecológicas particulares que, associadas às precárias condições materiais e conceituais de produção (pouca ou nenhuma terra para produção, deficiente estrutura de produção, baixa renda familiar, baixo nível de educação formal, baixo nível tecnológico, precária assistência técnica), afetam o desempenho das atividades agropecuárias.

Isto posto, cabe explicar que, uma vez estabelecidas as condições objetivas de produção e obedecendo a uma racionalidade particular, condizente com tais condições, o agricultor toma e executa decisões estratégicas que o situam nos diferentes níveis de acumulação e possibilidades de reprodução (ALVES, 2005).

Relativamente aos agricultores familiares com perfil de atendimento pelo Pronaf B no semiárido, o tipo de racionalidade pode encontrar abrigo no conceito de camponês elaborado por CHAYANOV (1974). Este autor relaciona as principais preocupações do campones à manutenção e à reprodução familiar. Ou seja, em primeiro lugar estão em jogo a sua sobrevivência e reprodução. Em função dessa racionalidade própria, sua prática cotidiana o conduz a tomar decisões com base no bom senso, no conhecimento empírico e na visão global sobre seu meio.

\footnotetext{
${ }^{6}$ Nas tabulações especiais realizadas com dados do Censo Agropecuário 2006, definiram-se inicialmente dois grupos: não familiares e familiares "pronafianos". Em seguida, o grupo de "pronafianos" foi estratificado em cinco subgrupos (A, B, C, D, E), levando em conta: renda bruta anual familiar e percentual oriundo de atividades desenvolvidas no interior do estabelecimento; se é assentado da reforma agrária; e o número de empregados assalariados permanentes.
} 
As particularidades do semiárido e dos agricultores enquadráveis no Pronaf B revelam a magnitude do problema social com o qual se deparam as instituições de desenvolvimento nordestinas. O desafio particular é do Banco do Nordeste do Brasil (BNB), pela responsabilidade de ser a principal instituição financeira a operacionalizar o Pronaf B em sua área de atuação. Nesse contexto, considera-se relevante o esforço de compreender as condições materiais e técnicas de produção, assim como as estratégias de reprodução social que adotam beneficiários do Pronaf B no semiárido brasileiro, objetivo central deste texto ${ }^{7}$. O embasamento empírico das análises está descrito no item metodologia.

Além desta introdução e das considerações finais, o texto está distribuído em três seções. Na segunda seção, são descritos os procedimentos metodológicos adotados no estudo; na terceira, são analisadas as condições materiais e técnicas de produção nas unidades familiares; na quarta, analisam-se as estratégias de produção e reprodução social adotadas por esses agricultores.

\section{PROCEDIMENTOS METODOLÓGICOS}

As informações utilizadas neste texto foram obtidas de BNB (2012), oriundas de uma pesquisa de campo realizada no ano de 2012 em toda a área de atuação do BNB, em parceria com a empresa de pesquisa e consultoria Datamétrica, para avaliar o Pronaf.

A pesquisa original adotou o modelo quase experimental, considerando duas categorias de entrevistados: 1) controle; e 2) tratamento. Em função da inexistência de cadastros com nomes e endereços de agricultores não beneficiários, para composição da categoria controle, foi feita a opção pelos beneficiários mais recentes do Programa (aqueles que tivessem um único contrato de crédito com o $\mathrm{BNB}$, assinado há menos de um ano). A categoria tratamento foi composta por beneficiários com mais de um contrato e mais de um ano de participação no Programa.

A base amostral foi construída a partir do cadastro de clientes do Pronaf BNB, da totalidade dos municípios abrangidos (Tabela 1) e da quantidade de contratos de crédito concedidos nesses municípios em 2012.

\footnotetext{
${ }^{7}$ No contexto aqui analisado, entende-se como reprodução social dos agricultores um dado patamar de renda assegurado pela unidade de produção (da qual dependem economicamente), que lhes garanta a sobrevivência, além da permanência na unidade de produção e na mesma categoria social a que pertencem (SILVA NETO; DEZEN, SANTOS, 2009).
} 
Tabela 1 - Municípios abrangidos pelo Pronaf, por tipologia PNDR: dentro e fora do semiárido

\begin{tabular}{lrrrrrr}
\hline \multirow{2}{*}{ Tipologia PNDR } & \multicolumn{2}{c}{ Total } & \multicolumn{2}{c}{ Semiárido } & \multicolumn{2}{c}{ Fora do semiárido } \\
\cline { 2 - 8 } & $(\%)$ & $(\mathrm{N})$ & $(\%)$ & $(\mathrm{N})$ & $(\%)$ & $(\mathrm{N})$ \\
\hline Baixa renda & 30 & 595 & 21 & 236 & 42,09 & 359 \\
Estagnada & 34 & 684 & 34 & 380 & 35,64 & 304 \\
Dinâmica & 33 & 655 & 45 & 513 & 16,65 & 142 \\
Alta renda & 3 & 50 & - & 2 & 5,63 & 48 \\
\hline Total & 100 & 1.984 & 100 & 1.131 & 100,00 & 853 \\
\hline
\end{tabular}

Fonte: BNB (2012).

Inicialmente, sortearam-se 120 municípios, de forma aleatória e proporcional à quantidade de contratos. Ao se constatar que alguns dos grupos (comum C, comum D e comum E) não abrigavam os quantitativos de beneficiários previstos na amostra (Tabela 3), sortearam-se, sequencialmente, outros municípios daquela base, até que cada um dos grupos mencionados atingisse o quantitativo requerido. Desta forma, a quantidade de municípios efetivamente escolhidos foi ampliada para 153, classificados de acordo com a tipologia da Política Nacional de Desenvolvimento Regional (PNDR) e a localização dentro e fora do semiárido (Tabela 2).

Tabela 2 - Municípios sorteados por tipologia PNDR: dentro e fora do semiárido

\begin{tabular}{|c|c|c|c|c|c|c|}
\hline \multirow{2}{*}{ Tipologia PNDR } & \multicolumn{2}{|c|}{ Total } & \multicolumn{2}{|c|}{ Semiárido } & \multicolumn{2}{|c|}{ Fora do semiárido } \\
\hline & $(\%)$ & $(\mathrm{N})$ & $(\%)$ & $(\mathrm{N})$ & $(\%)$ & $(\mathrm{N})$ \\
\hline Baixa renda & 31 & 47 & 22 & 18 & 40 & 29 \\
\hline Estagnada & 32 & 49 & 33 & 27 & 31 & 22 \\
\hline Dinâmica & 31 & 48 & 43 & 35 & 18 & 13 \\
\hline Alta renda & 6 & 9 & 1 & 1 & 11 & 8 \\
\hline Total & 100 & 153 & 100 & 81 & 100 & 72 \\
\hline
\end{tabular}

Fonte: BNB (2012).

No processo de amostragem, definiu-se em 3.000 a quantidade de clientes ${ }^{8}$ para entrevista (questionários semiestruturados), a partir de sorteio aleatório nos diversos grupos do Pronaf (Tabela 3), nos 153 municípios definidos (Tabela 2), contemplando as categorias controle e tratamento.

\footnotetext{
${ }^{8}$ A adoção do termo "cliente", no presente contexto, tem o objetivo de esclarecer que os sujeitos selecionados para entrevista eram ativos (com operações em ser no Programa) no momento da realização da amostragem.
}

DOI: http://dx.doi.org/10.22295/grifos.v30i51.5608 | Edição Vol. 30, Núm. 51, 2021. 
Tabela 3 - Distribuição da amostra por grupos do Pronaf e categorias definidas na área de atuação do BNB

\begin{tabular}{lccc}
\hline Grupos & Tratamento & Controle & Total \\
\hline A & 200 & Não & 200 \\
B & 300 & 300 & 600 \\
Comum C & 300 & 300 & 600 \\
Comum D & 300 & 300 & 600 \\
Comum E & 300 & 300 & 600 \\
Mais Alimentos $(*)$ & 200 & 1 & 200 \\
Mulher $(*)$ & 200 & 1 & 200 \\
\hline Total & 1.800 & 1.200 & 3.000 \\
\hline
\end{tabular}

Fonte: BNB (2012).

(*) Como as linhas de créditos mulher e mais alimentos são concedidas a produtores dos grupos acima definidos (A, B, C, D e E), seus grupos de controle (com 200 famílias, cada) foram constituídos pelas mesmas famílias sorteadas para os grupos de controle daqueles grupos, não havendo, portanto, acréscimo no tamanho da amostra.

Para a elaboração deste trabalho, procedeu-se a um recorte na base de dados daquela pesquisa, selecionando somente os pronafianos do grupo B localizados no semiárido brasileiro 9 .

Dos 600 questionários dirigidos a esse segmento no estudo original, 445 destinaramse a agricultores do semiárido ${ }^{10}$. Os principais resultados são apresentados e discutidos a seguir.

\section{CARACTERÍSTICAS SOCIAIS E DOS MEIOS DE PRODUÇÃO}

O perfil social dos beneficiários do Pronaf B objeto deste estudo distancia-se do observado pelo Censo Agropecuário de 2006 (IBGE, 2012) para agricultores familiares do semiárido, no que diz respeito à faixa etária, considerando-se que os entrevistados são os chefes das famílias. Veja-se que eles são relativamente jovens $(69,4 \%$ dos entrevistados com idade entre 0 e 39 anos), enquanto que os dados daquele Censo (IBGE, 2012) apontam que a maioria dos chefes dos estabelecimentos $(71,4 \%)$ tem idade acima de 45 anos.

\footnotetext{
${ }^{9}$ Os dados relativos ao semiárido brasileiro incluem a área da Superintendência do Desenvolvimento do Nordeste (Sudene) em Minas Gerais (BRASIL. MIN, 2005). Portanto, ultrapassam a fronteira nordestina. A decisão do recorte pelo semiárido, nesse trabalho, é justificada pela relevância territorial e, principalmente, pelas especificidades edafoclimáticas e socioeconômicas que o caracterizam, sugerindo a necessidade de novos estudos e abordagens que forneçam informações para subsidiar políticas públicas locais.

${ }^{10}$ Adverte-se que as análises desconsideraram o recorte (tratamento; controle) adotado na pesquisa original e que, em função da existência de 66 questionários com respostas inválidas para o bloco de perguntas sobre "posse e uso da terra", as análises relativas a esse quesito foram realizadas com base nas respostas válidas (total de 379), conforme tabelas 4 e 5.
} 
Em relação à educação formal, igualmente, os dados mostram certa distância em relação ao perfil observado para a agricultura familiar do semiárido, na medida em que revela boa capacidade de leitura (sabem ler e escrever: 74,8\%; concluíram o ensino fundamental I: 46,7\%; são analfabetos: 17,2\%). Segundo os dados do Censo (IBGE, 2012), somente 13,5\% dos agricultores com perfil pronafiano B sabem ler e escrever; os que declararam não saber ler e escrever representam quase metade (45,3\%). Em relação a gênero, observa-se uma distribuição equitativa (54,4\% são mulheres).

Em relação à moradia, há aproximação com os números observados pelo IBGE (2012), na medida em que a maioria reside em casas próprias, em terreno próprio $(87,2 \%)$, construídas de alvenaria (84,0\%), com valor médio de mercado de R\$21.618,27 (BNB, 2012). Considerando que a maioria reside no meio rural (89\%), avalia-se como bom o acesso a redes públicas de abastecimento de água (44,3\% das residências) e elétrica $(96,6 \%$ das residências), conforme BNB (2012).

Como apontado na introdução deste documento, a diferenciação entre agricultores, em parte, é produzida pelo desenvolvimento capitalista e se manifesta nas condições materiais, no conhecimento, nas técnicas, no acesso à informação e nas formas objetivas de integração com o meio. Os dados a seguir analisados validam essa teoria.

\section{Posse e uso da terra}

A disponibilidade de terras é uma condição material importante para a produção que, aliada a outros meios materiais, determina os níveis de acumulação e possibilidades de reprodução dos agricultores. Neste sentido, a primeira revelação importante na análise diz respeito à existência de quase 18\% (68 entrevistados) sem terras próprias, considerando-se as respostas válidas (Tabela 4). Esses clientes são os que mais adotam estratégias como arrendamento e parceria, além do uso de áreas cedidas por terceiros. Dos que se utilizam dessas estratégias, 73,8\% (62/84*100) declararam não ter terra própria, mas a maioria utiliza a modalidade de terras cedidas por terceiros (Tabela 4). A área média explorada nas três modalidades é de, respectivamente, 4,4, 8,9 e 7,9 hectares (Tabela 5).

Por outro lado, pode parecer irreal a informação de que seis dos agricultores entrevistados "sem terra própria" não registram o uso agropecuário de qualquer área própria, 
arrendada, em parceria ou cedida por terceiros, como mostrado na Tabela 4. Pode-se questionar por que clientes sem terra e sem acesso a outras modalidades de uso procurariam instituições bancárias para obter financiamento. O fato é que o Programa permite o financiamento de atividades não agropecuárias. E, como mostrado mais a frente, a sua prática é real, como parte de uma estratégia de sobrevivência, abrigada pelo Programa e reconhecida como alternativa econômica menos susceptível às intempéries climáticas do semiárido. Cabe explicar que, especialmente nos casos mais bem-sucedidos do Pronaf B, os ganhos com essas atividades ultrapassam a renda máxima para obtenção da Declaração de Aptidão ao Pronaf (DAP), sem, contudo, tornar o beneficiário apto a enquadrar-se em grupos superiores do Programa. Tal limitação ocorre em função das exigências mínimas de renda proveniente da atividade agropecuária e das condições de acesso à terra e infraestrutura, entre outros, podendo afetar de forma significativa o desenvolvimento e a ampliação de atividades não agropecuárias. Além disso, existe uma norma do Pronaf $\mathrm{B}$ que associa o custeio ao investimento, limitando a $35 \%$ do financiamento total. Essa norma não condiz com as necessidades crescentes de matéria-prima para o desenvolvimento posterior dessas atividades não agropecuárias, podendo impactar o seu desenvolvimento.

Tabela 4 - Distribuição das terras exploradas por estratos de área entre beneficiários do Pronaf B no semiárido

\begin{tabular}{lccccc}
\hline & \multicolumn{5}{c}{ Quantidade de agricultores } \\
\cline { 2 - 6 } Estratos de área própria & Total & $\begin{array}{c}\text { Usa terra } \\
\text { arrendada (1) }\end{array}$ & $\begin{array}{c}\text { Usa terra em } \\
\text { parceria (2) }\end{array}$ & $\begin{array}{c}\text { Usa terra } \\
\text { cedidas (3) }\end{array}$ & $\begin{array}{c}\text { Subtotal } \\
(1,2,3)\end{array}$ \\
\hline Sem terra própria & & 18 & 9 & 35 & 62 \\
Até 10 ha de área própria & 241 & 8 & 5 & 8 & 21 \\
De 10,1 a 50 ha de área própria & 62 & 1 & 0 & 0 & 1 \\
Acima de 50 ha de área própria & 8 & 0 & 0 & 0 & 0 \\
Respostas válidas $^{2}$ & 379 & 27 & 14 & 43 & 84 \\
\hline
\end{tabular}

Fonte: BNB (2012).

Notas: ${ }^{1}$ Seis clientes "sem terra própria" declararam não adotar qualquer das modalidades de uso de área própria, arrendada, em parceria ou cedida por terceiros. Desta forma, a quantidade do subtotal $(1,2,3)$ para a linha "sem terra própria" (62) não coincide com aquela da coluna total (68).

2 Dos 445 questionários aplicados, 66 tiveram respostas inválidas para esta questão, totalizando 379 respostas válidas.

Entre os beneficiários com respostas válidas, observa-se que 82,1\% detêm áreas próprias, cujo tamanho médio por beneficiário não ultrapassa os 10,2 hectares (Tabela 5), dos quais, 77,5\% contam com, no máximo, 10 hectares (Tabela 4). Os agricultores com áreas superiores a 10 hectares representam apenas 22,5\% dos que dispõem de área própria e 18,5\% do total de entrevistas válidas (Tabela 4). 
Tabela 5 - Posse e uso da terra entre beneficiários do Pronaf B no semiárido

\begin{tabular}{|c|c|c|c|}
\hline $\begin{array}{l}\text { Terras exploradas pelas famílias } \\
\text { (hectares) }\end{array}$ & Área média & Respostas válidas & $\begin{array}{c}\text { Respostas válidas } \\
(\%)\end{array}$ \\
\hline Área total explorada ${ }^{1}$ & 11,2 & 379 & 100,0 \\
\hline Área própria ${ }^{2}$ & 10,2 & 311 & 82,1 \\
\hline Área arrendada & 4,4 & 34 & 9,0 \\
\hline Área em parceria & 8,9 & 14 & 3,7 \\
\hline Área cedida & 7,9 & 43 & 11,3 \\
\hline
\end{tabular}

Fonte: BNB (2012).

Notas: ${ }^{1}$ Dos 445 questionários aplicados, 66 tiveram respostas inválidas para esta questão, totalizando 379 respostas válidas.

${ }^{2}$ Dos 379 questionários válidos, 68 declararam não possuir terras, restando 311 entrevistados com terras próprias.

Importante ressaltar a coerência entre os dados aqui apresentados e aqueles apurados pelo IBGE no Censo Agropecuário 2006 (IBGE, 2012). Segundo aquele Censo, dos 1,24 milhão de estabelecimentos agropecuários com perfil de atendimento pelo Pronaf $\mathrm{B}$ no semiárido, 54,9\% têm área inferior a 5 hectares. Em associação com as características edafoclimáticas apontadas na introdução deste texto, a limitação de terras e a falta de alternativas aos agricultores do semiárido pode resultar em intensa pressão sobre os recursos naturais (ECHEVERRI, 2005), podendo promover degradação e até processos de desertificação.

\section{Bens (físicos e agrícolas) e acesso à tecnologia}

A disponibilidade de capital físico e agrícola, associada à disponibilidade de terras e outros meios de produção, define os níveis de acumulação e possibilidades de reprodução social dos agricultores. No gráfico 1 apresentam-se informações sobre este aspecto. Observase, por exemplo, que uma parte dos agricultores entrevistados prioriza a posse de meios de transporte motorizado, já que 30\% deles possuem motocicletas e 6\% dispõem de automóveis/utilitários. De fato, além de tornar-se meio de transporte entre as comunidades rurais e a sede municipal, nos anos recentes ocorre a troca paulatina de animais de montaria (tradicional meio para tocar os rebanhos) pelas motocicletas. A instalação de concessionárias em diversas cidades interioranas e a facilidade de financiamento do veículo têm estimulado a sua aquisição.

Relativamente a máquinas e equipamentos agrícolas, vale registrar que: 1) somente $14 \%$ dos beneficiários possuem pulverizador/bomba (Gráfico 1);2) alguns equipamentos e 
implementos agrícolas constantes na relação da pesquisa (tais como trator, grade e tanque de resfriamento de leite) mostram-se inadequados para as atividades desenvolvidas por clientes do Pronaf B, em função das áreas exploradas, mínimas e com baixo volume de produção; 3) além disso, tais equipamentos têm elevado custo, de qualquer forma inviabilizando sua aquisição por agricultores pobres, o que leva algumas prefeituras da região a disponibilizarem trator e grade antes do período chuvoso para preparar áreas de produção; 4) plantadeiras, cultivador (capinadeira de tração animal) e arado de aiveca são pouco utilizados, evidenciando que implementos de tração animal estão caindo em desuso neste segmento de agricultores (Gráfico 1); 5) ainda é reduzido o uso de computadores, predominando entre os entrevistados mais jovens ou com filhos ainda jovens (em 50\% das famílias com computadores, a idade média é inferior a 30 anos, conforme dados de campo).

Gráfico 1 - Posse de capital físico agrícola entre beneficiários do Pronaf B no semiárido (Em \%)

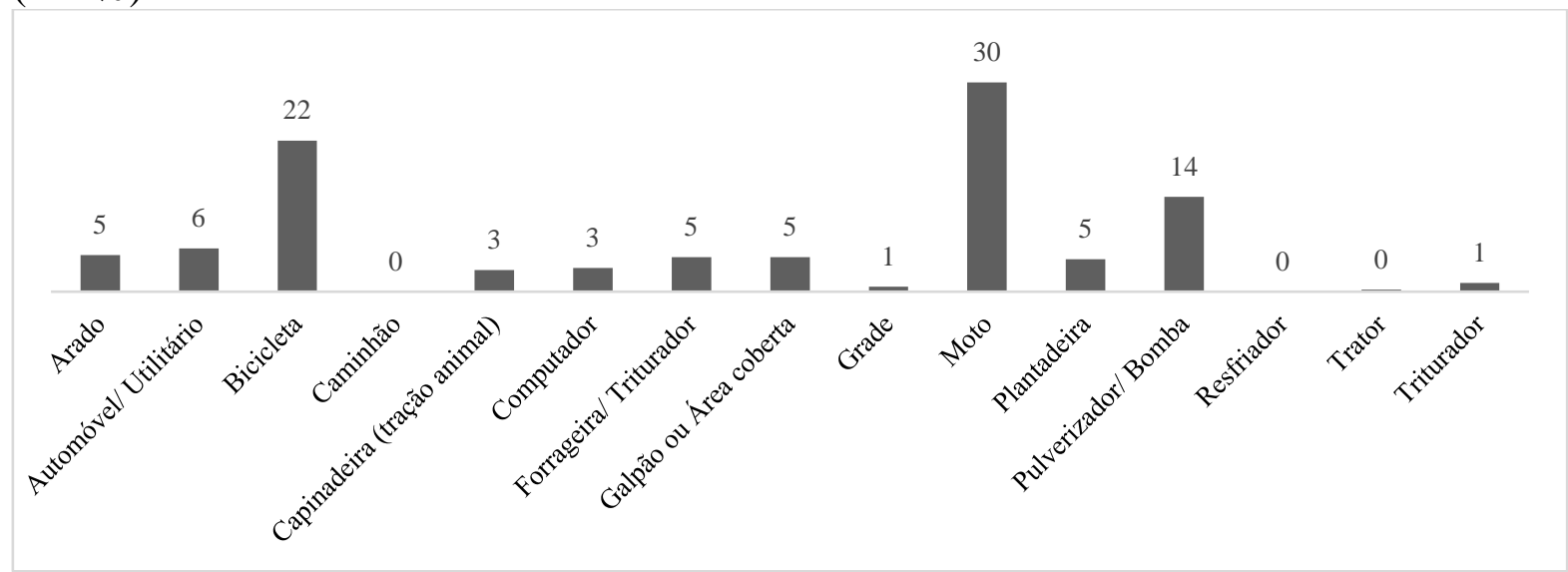

Fonte: BNB (2012).

Os dados são claros quanto à indicação de que os agricultores pobres permanecem à margem do acesso a conhecimentos e orientação técnica via empresas de extensão rural. Quase $84,7 \%$ dos entrevistados afirmaram não receber qualquer orientação técnica. Os poucos que declararam ter acesso ao serviço, apontaram o sistema público assistência técnica e extensão rural (Ater) como o principal prestador que, por sua vez, atravessa dificuldades com deficiência de pessoal, recursos e estrutura inadequada para o trabalho dos extensionistas (BNB, 2012). Isso dificulta o atendimento e compromete a qualidade, contribuindo para que o serviço muitas vezes se limite à fiscalização. Tais limitações são reconhecidas pelo corpo técnico que, segundo Landini (2015), acreditam ser a insuficiência de profissionais um dos mais importantes problemas enfrentados pelo sistema Ater brasileiro. 
De fato, as deficiências apontadas acima configuram-se como entrave significativo para o êxito do Pronaf B, conforme apontam Zani e Costa (2014), na medida em que dificultam o acesso dos agricultores a informações e a determinadas práticas, técnicas ou tecnologias no processo produtivo. Em associação com as condições materiais de produção, esses acessos (ou a inexistência deles) determinam as condições objetivas de desenvolvimento dos agricultores.

No Gráfico 2, verifica-se que algumas práticas, como a inseminação artificial e a sincronização de cio, praticamente inexistem entre os entrevistados. A maioria (acima de $80 \%$ dos entrevistados) não realiza também produção e armazenamento de forragem, estação de monta, higienização do ambiente de ordenha, irrigação, acompanhamento de mercado, técnicas de embalagem ou registro contábil ${ }^{11}$.

Assim como acontece com determinados bens físicos, algumas dessas práticas seriam inviáveis do ponto de vista econômico, em função do custo que acarretam, devido ao reduzido número de animais e ao baixo volume de produção. Outras, a exemplo do acompanhamento de mercado, revelam pouca utilidade para agricultores com o perfil aqui apresentado. A realidade é que comercializam somente o excedente do que as condições materiais e edafoclimáticas permitem produzir, preferencialmente em mercados de proximidade (parentes, vizinhos, comunidade, feira).

Portanto, a escala, as condições de produção e a forma de comercialização predominante não justificam práticas como inseminação artificial, sincronização de cio, aquisição de embalagens, irrigação, meio de transporte e acompanhamento de mercado.

\footnotetext{
${ }^{11}$ Relativamente à prática de irrigação, dados existem que provam o elevado custo. Portanto, mais apropriada seria a adoção de tecnologias de convivência com o semiárido que resultem no aumento da produção, a exemplo das cisternas, a reutilização de água de uso doméstico na produção de hortaliças e fruteiras, quintais produtivos e mandalas, entre outras práticas. Vale salientar que estas práticas são mais adequadas ao público do Pronaf B e ao semiárido, por serem sustentáveis e de menor custo que aquelas em geral adotadas por agricultores com perfil produtivo do agronegócio. Porém, o instrumento de coleta de dados não explorou estes aspectos, impossibilitando a sua análise neste trabalho.
} 
Gráfico 2 - Práticas agropecuárias adotadas entre beneficiários do Pronaf B (Em \%)

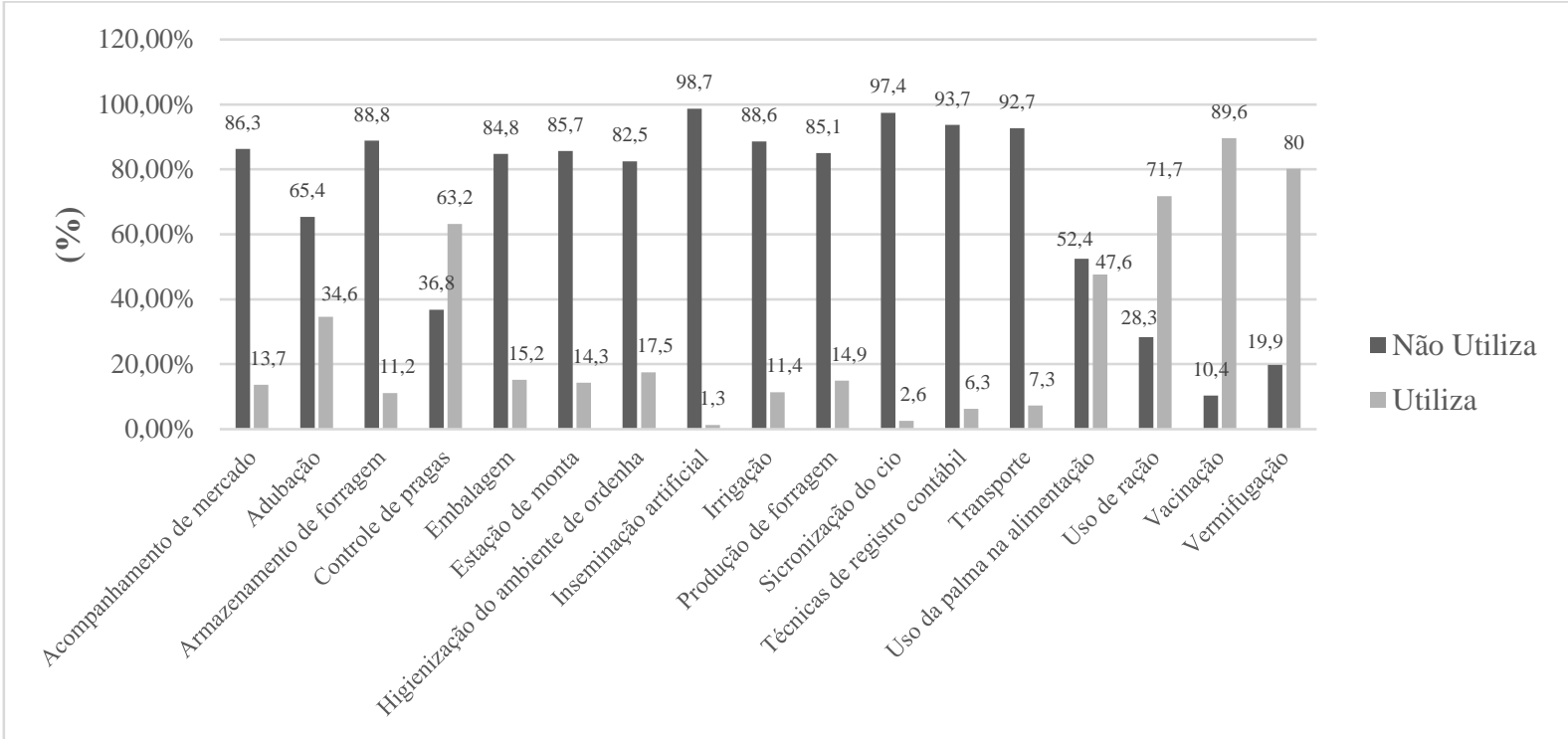

Fonte: BNB (2012).

Por outro lado, algumas práticas preventivas revelam-se pelo elevado uso entre esses agricultores. Destacam-se a vacinação (exigência legal para algumas doenças) e a vermifugação (adotadas por 89,6\% e $80 \%$ dos entrevistados, respectivamente), difundidas em todo o Nordeste (mesmo entre agricultores de menor porte) e cujo uso representa redução de risco de perda de animais (gráfico 2). Significativo também é o percentual dos que realizam controle de pragas (63,2\% dos entrevistados), apesar da pouca área média cultivada por esses agricultores. Em certa medida, os dados desmitificam a ideia de que o agricultor familiar pobre não usa defensivos químicos, servindo de alerta sobre os riscos ao meio ambiente (contaminação do solo) e à saúde humana (intoxicação). O desconhecimento de grande parte dos agricultores sobre os riscos a que estão submetidos os conduz ao não uso ou ao uso parcial de equipamentos de proteção individual (EPIs) durante as aplicações desses defensivos. Registre-se que os riscos persistem, mesmo nos casos em que se utilizam EPIs, em função da precariedade dos equipamentos e do desconhecimento das técnicas adequadas de manejo de agrotóxicos e descarte de embalagens.

Sobre a alimentação dos animais, os dados revelam um percentual relativamente elevado de agricultores que fornecem suplementação concentrada $(71,7 \%)$, podendo ser reflexo da baixa capacidade de produção e conservação de forragem (BNB, 2012). O que acontece na prática é que, no período mais seco do ano, quando acaba a pastagem nativa, os agricultores são obrigados a adquirir ração concentrada. Nesse período, parte dos animais é 
vendida para a aquisição da ração que manterá vivo o restante do rebanho. Essa é uma das diversas estratégias que esses agricultores adotam de modo a se manterem produzindo e se reproduzindo, conforme mostrado no item que se segue.

\section{ESTRATÉGIAS DE PRODUÇÃO E REPRODUÇÃO SOCIAL}

Dadas as condições materiais, tecnológicas e de conhecimento, assim como as condições de integração com o meio em que vivem, os agricultores elaboram estratégias de produção e reprodução, conforme apresentado a seguir.

\section{Obtenção de renda}

A produção, embora em pequenas áreas e dependente das características de clima e solos e da disponibilidade hídrica, é diversificada. Plantam-se fruteiras, leguminosas, forrageiras e culturas hortícolas. Essa é uma estratégia utilizada para maximização da produção nas reduzidas áreas, importante para a segurança alimentar da família e a venda de excedentes que permite aquisição de bens e serviços não produzidos internamente.

No âmbito dessa mesma estratégia, 38,7\% realizam consórcio entre culturas agrícolas. Dentre os que consorciam, a prática é mais comum entre as culturas do feijão e do milho $(58,1 \%)$, mas também se observa entre feijão e mandioca; feijão, mandioca e milho; feijão, milho e arroz; feijão, melancia e milho; e feijão, abóbora e milho, dentre outros.

Registre-se que o consórcio de culturas de subsistência é uma prática amplamente difundida entre agricultores familiares e não se associa ao emprego de alta tecnologia nem visa à obtenção de produções elevadas ${ }^{12}$. Com isso, os agricultores buscam o aproveitamento máximo da terra disponível minimizando o uso de mão de obra, por serem ambos os recursos mais escassos na unidade familiar. Essa prática permite a maior produção por área, promove maior aproveitamento de mão de obra e apresenta as vantagens de reduzir o risco de perda da produção decorrente de instabilidades climáticas. Além disso, o feijão, por ser uma leguminosa, fixa o nitrogênio no solo, o que beneficia a outra cultura.

\footnotetext{
${ }^{12} \mathrm{O}$ consorciamento permite a exploração concomitante, na mesma área, de pelo menos duas culturas de ciclos e arquiteturas vegetativas diferentes. Essa prática impede a utilização, em maior grau, de técnicas agrícolas modernas, a exemplo da mecanização (VIEIRA, 1989).
}

DOI: http://dx.doi.org/10.22295/grifos.v30i51.5608 | Edição Vol. 30, Núm. 51, 2021. 
As fontes de renda desses agricultores são diversificadas. Além das atividades agropecuárias e não agropecuárias desenvolvidas dentro da unidade familiar ou próximo a ela, cerca de $15,7 \%$ dos entrevistados mantêm ocupações no mercado de trabalho local, fora do negócio familiar, distribuídas conforme Tabela 6. Destes, 18,5\% ocupam-se da agropecuária e os demais em atividades relacionadas a comércio e serviços (35,7\%), serviço público $(11,4 \%)$, indústria $(4,3 \%)$, entre outros.

Tabela 6 - Ocupações no mercado local, fora do negócio familiar, entre beneficiários do Pronaf B no semiárido

\begin{tabular}{lcc}
\hline Ocupações & Quantidade & $(\%)$ \\
\hline Agricultura & 12 & 17,1 \\
Pecuária & 1 & 1,4 \\
Indústria & 3 & 4,3 \\
Comércio & 7 & 10,0 \\
Serviços & 18 & 25,7 \\
Serviço público & 8 & 11,4 \\
Profissional liberal & 3 & 4,3 \\
Outros & 9 & 12,9 \\
Não sabem/não responderam & 9 & 12,9 \\
\hline Total & 70 & 100,0 \\
\hline
\end{tabular}

Fonte: BNB (2012).

Os benefícios sociais oferecidos pelo governo federal - Bolsa Família, Programa de Erradicação do Trabalho Infantil (Peti), aposentadoria, pensão, Benefício da Prestação Continuada (BPC) idoso e deficiente, dentre outros -, alcançam 58,2\% das famílias dos entrevistados e contribuem para a reprodução social do grupo. A média de renda oriunda desses benefícios é de $\mathrm{R} \$ 173,73$ mensais por família.

\section{Acesso ao crédito}

As condições efetivas de acesso a crédito subsidiam a decisão do agricultor em relação ao que produzir e o destino a ser dado. Por isso, influenciam na estratégia de produção e, em última instância, na definição de estratégias de reprodução do grupo familiar.

A este respeito, verifica-se que parte significativa dos entrevistados realizou pelo menos duas operações de crédito via Pronaf B (53,3\%). Um percentual de 27,6\% desses agricultores realizou uma terceira operação, enquanto somente 9,9\% obtiveram financiamento pela quarta $\mathrm{vez}^{13}$. Os financiamentos destinaram-se principalmente a

\footnotetext{
${ }^{13}$ As condições operacionais dos financiamentos no âmbito do Agroamigo são: carência máxima de até doze meses e prazo máximo para pagamento de até 24 meses (incluso o período de carência). Mas varia de acordo
} 
investimentos, em função do caráter do Programa, que possibilita no máximo $35 \%$ de custeio associado por operação de crédito. Em tese, a prioridade ao investimento, confirmada pelos dados da Tabela $7(80,4 \%, 75,5 \%, 76,4 \%$ e $70,5 \%$, respectivamente, na primeira, na segunda, na terceira e na quarta operações), permite ao financiamento contribuir para a melhoria das condições materiais de produção. No entanto, pode afetar negativamente o desenvolvimento de atividades que necessitam de matéria-prima, como é o caso das não agropecuárias.

Tabela 7 - Finalidade dos financiamentos obtidos do Pronaf B no semiárido

\begin{tabular}{|c|c|c|c|c|c|c|c|c|}
\hline \multirow{2}{*}{ Finalidade do financiamento } & \multicolumn{2}{|c|}{ 1ํㅡ operação } & \multicolumn{2}{|c|}{ 2- operação } & \multicolumn{2}{|c|}{ 3- operação } & \multicolumn{2}{|c|}{ 4- operação } \\
\hline & Clientes & $(\%)$ & Clientes & $(\%)$ & Clientes & $(\%)$ & Clientes & $(\%)$ \\
\hline Investimento & 358 & 80,4 & 179 & 75,5 & 94 & 76,4 & 31 & 70,5 \\
\hline Custeio & 28 & 6,3 & 13 & 5,5 & 8 & 6,5 & 4 & 9,1 \\
\hline Investimento e custeio & 13 & 2,9 & 11 & 4,6 & 10 & 8,1 & 3 & 6,8 \\
\hline Não sabem/não responderam & 46 & 10,3 & 34 & 14,3 & 11 & 8,9 & 6 & 13,6 \\
\hline Total de tomadores/operação & 445 & 100,0 & 237 & 100,0 & 123 & 100,0 & 44 & 100,0 \\
\hline $\begin{array}{l}\text { \% em relação ao total de } \\
\text { entrevistados }\end{array}$ & & 100,0 & & 53,3 & & 27,6 & & 9,9 \\
\hline
\end{tabular}

Fonte: BNB (2012).

A declaração de pontualidade no pagamento das parcelas do financiamento é outro aspecto de destaque (Tabela 8). Os dados da pesquisa mostram elevados níveis de adimplência: financiamento 1 (92,4\%); financiamento 2 (91,1\%); financiamento $3(94,3 \%)$; financiamento 4 (88,6\%) (Tabela 8), em oposição à elevada inadimplência do Pronaf B nos primeiros anos de sua operacionalização, alcançando 63,9\% antes da criação do Agroamigo, conforme BNB (2010).

Tabela 8 - Situação dos financiamentos do Pronaf B no semiárido em relação à pontualidade no pagamento das parcelas

\begin{tabular}{lrrrrrrrr}
\hline \multirow{2}{*}{ Pontualidade das parcelas } & \multicolumn{2}{c}{ 1- operação } & \multicolumn{2}{c}{ 2- operação } & 3- operação & \multicolumn{4}{c}{ 4- operação } \\
\cline { 2 - 9 } & Clientes & $(\%)$ & Clientes & $(\%)$ & Clientes & $(\%)$ & Clientes & $(\%)$ \\
\hline Têm ou tiveram parcelas em atraso & 19 & 4,3 & 11 & 4,6 & 2 & 1,6 & 2 & 4,5 \\
Nunca tiveram parcela em atraso & 411 & 92,4 & 216 & 91,1 & 116 & 94,3 & 39 & 88,6 \\
Não sabem/não responderam & 15 & 3,4 & 10 & 4,2 & 5 & 4,1 & 3 & 6,8 \\
\hline Total de tomadores & 445 & 100,0 & 237 & 100,0 & 123 & 100,0 & 44 & 100,0 \\
\hline
\end{tabular}

Fonte: BNB (2012).

É fato, portanto, que ocorreu uma massificação do crédito entre os pobres do Nordeste rural a partir do início dos anos 2000, após a criação do Pronaf B. Isso, no entanto, 
possibilitou o crescimento nos níveis de inadimplência ${ }^{14}$ que, no caso do Nordeste, foram drasticamente reduzidos a partir da criação e adoção da metodologia do Agroamigo, em $2005^{15}$, reforçada pela série de medidas inibidoras tomadas no âmbito do Ministério do Desenvolvimento Agrário (MDA), no ano de 2007, dentre as quais: obrigatoriedade de receber, dos bancos, um relatório com a situação de cada município em que houvesse financiamento; suspensão de novos financiamentos em municípios cuja inadimplência atingisse $15 \%$ dos contratos; proibição de novos financiamentos a agricultores que obtiveram o crédito, mas não o pagaram pontualmente.

Enfim, a aplicação da metodologia do Agroamigo associada ao conjunto das medidas mencionadas tem contribuído para a redução dos níveis de inadimplência no Pronaf $\mathrm{B}$, conforme indicam os dados empíricos apresentados na Tabela 8.

Cabe observar, no entanto, até que ponto essas condições impostas aos mutuários do Pronaf B têm influenciado os níveis de satisfação dos clientes. Apesar de não fazerem referência direta às mudanças ocorridas no processo de operacionalização do Programa, as questões postas na Tabela 9 dão indicações da influência que podem ter exercido nos níveis de satisfação dos clientes relativamente a alguns itens do financiamento e do serviço de assistência técnica.

Tabela 9 - Satisfação dos mutuários residentes no semiárido em relação ao Pronaf B

\begin{tabular}{|c|c|c|c|c|c|c|c|c|c|c|c|}
\hline \multirow{2}{*}{ Itens avaliados } & \multicolumn{11}{|c|}{ Número de respostas por nível de satisfação (notas 1 a 10) } \\
\hline & 1 a 3 & $(\%)$ & 4 a 6 & $(\%)$ & 7 a 9 & $(\%)$ & 10 & $(\%)$ & NA & $(\%)$ & Total \\
\hline Valor do financiamento & 4 & 0,9 & 29 & 6,5 & 141 & 31,7 & 269 & 60,4 & 2 & 0,4 & 445 \\
\hline Prazo/valor das prestações & 3 & 0,7 & 25 & 5,6 & 160 & 36,0 & 252 & 56,6 & 5 & 1,1 & 445 \\
\hline $\begin{array}{l}\text { Exigência do banco para } \\
\text { liberação }\end{array}$ & 13 & 2,9 & 51 & 11,5 & 189 & 42,5 & 184 & 41,3 & 8 & 1,8 & 445 \\
\hline $\begin{array}{l}\text { Adequação dos itens do projeto } \\
\text { à realidade da atividade } \\
\text { financiada }\end{array}$ & 8 & 1,8 & 55 & 12,4 & 179 & 40,2 & 175 & 39,3 & 28 & 6,3 & 445 \\
\hline $\begin{array}{l}\text { Assistência técnica pós- } \\
\text { financiamento }\end{array}$ & 126 & 28,3 & 74 & 16,6 & 95 & 21,3 & 121 & 27,2 & 29 & 6,5 & 445 \\
\hline $\begin{array}{l}\text { Facilidade para renegociação do } \\
\text { pagamento }\end{array}$ & 4 & 0,9 & 11 & 2,5 & 41 & 9,2 & 53 & 11,9 & 336 & 75,5 & 445 \\
\hline
\end{tabular}

Fonte: BNB (2012).

Nota: o número 1 corresponde à pior nota atribuída, e o número 10 à melhor nota.

14 A inadimplência observada em seus anos iniciais, segundo Abramovay (2008), teria relação com a disseminação de uma cultura do não pagamento, feita por organizações locais, justificada pela possibilidade de renegociação vantajosa (ABRAMOVAY, 2008).

${ }^{15} \mathrm{O}$ Agroamigo é uma metodologia de operacionalização que permite atendimento diferenciado aos agricultores pobres, objetivando ampliar o número de beneficiários do Pronaf B e garantir atendimento de qualidade com redução da inadimplência (BNB, 2015). 
Os dados mostram que, de um modo geral, o Pronaf B obtém boa avaliação dos entrevistados. Valor do financiamento e prazo/valor da prestação receberam a nota 10 de mais de $55 \%$ dos entrevistados. Nestes itens, somando-se os julgamentos com nota de 7 a 9 , os percentuais atingem $31,7 \%$ e $36 \%$, respectivamente.

Pouco mais de $41 \%$ dos entrevistados estão de pleno acordo com as exigências do banco para liberação do crédito; percentual similar atribui notas de 7 a 9 ao mesmo item; e $39,3 \%$ consideram que os itens do projeto são adequados à realidade da atividade.

O item com a pior avaliação refere-se a serviços de assistência técnica, visto que $28,3 \%$ e 16,6\%, respectivamente, atribuíram notas de 1 a 3 e 4 a 6 . Apesar de receber avaliação negativa de parte significativa dos entrevistados, o serviço de assistência técnica foi considerado de médio a bom (notas 7 a 9) por 21,3\% e ótimo (nota 10) por 27,2\% dos respondentes.

\section{Acesso aos mercados (insumos e produtos)}

Os tipos de mercado aos quais os agricultores têm acesso, seja de insumos ou de venda dos produtos, bem como as formas de acesso a esses mercados, resultam de estratégias elaboradas por eles, buscando garantir, em última instância, a reprodução social do grupo familiar, como pode ser observado a seguir.

Os insumos necessários à produção, segundo declaração da maior parte dos entrevistados $(68,1 \%)$ são adquiridos no mercado local; somente $7,4 \%$ buscam os insumos em centros revendedores vizinhos (Tabela 10). Ainda sobre insumos, chama a atenção a afirmação "não se aplica”, feita por 21,6\% dos entrevistados. Dentre outras possibilidades, isso pode significar que parte dos insumos necessários à produção é oriunda da própria unidade de produção, tornando desnecessária a intermediação de instituições externas. Podese considerar tal hipótese plausível, na medida em que se está tratando de um agricultor reconhecidamente descapitalizado e pouco integrado aos mercados de insumos. 
Tabela 10 - Origem dos produtos adquiridos pelos beneficiários do Pronaf B no semiárido

\begin{tabular}{lrr}
\hline Origem dos insumos para produção & $\begin{array}{c}\text { Quantidade de } \\
\text { respostas }\end{array}$ & $(\%)$ \\
\hline Mercado local & 303 & 68,1 \\
Grandes centros revendedores do estado e da região & 6 & 1,4 \\
Centros revendedores vizinhos & 33 & 7,4 \\
Emater & 3 & 0,6 \\
Associação & 1 & 0,2 \\
Não se aplica & 96 & 21,6 \\
NS/NR & 3 & 0,7 \\
\hline Total & 445 & 100,0 \\
\hline
\end{tabular}

Fonte: BNB (2012).

A maior parte dos entrevistados $(64,9 \%)$ considera de boa $(64,9 \%)$ a média $(11,2 \%)$ a qualidade dos insumos que precisam adquirir. A boa avaliação da qualidade desses produtos pode estar relacionada com o fato de serem originários dos mercados locais, em cujas negociações há contato direto entre comprador e vendedor. Essa forma de venda, por sinal, dispensa a intermediação da organização associativa, de acordo com afirmação de 74,4\% dos entrevistados, apesar de quase metade deles $(49,2 \%)$ declarar-se como associada a alguma organização associativa (BNB, 2012). A verdade é que essa proximidade estimula o vendedor a realizar controle de qualidade dos produtos, tornando-os confiáveis aos olhos do comprador (WILKINSON, 2002), inclusive contribuindo para o fortalecimento de vínculos de confiança.

Outro aspecto relevante sobre insumos, é que poucos agricultores mantêm estoque $(17,5 \%)$ e não costumam adquiri-los em troca do compromisso de entregar produção futura, conforme afirmam $95,7 \%$; ainda, mais da metade $(54,8 \%)$ realiza pesquisa de preços antes de fechar a compra dos insumos necessários à produção (Tabela 11). Tal preocupação refletese nos preços que, na avaliação de 68,5\% dos entrevistados, encontram-se na média do que pagam os seus vizinhos (BNB, 2012).

Enfim, o conjunto de condições e características dadas faz que, na prática, esses agricultores prefiram utilizar insumos produzidos internamente ou adquiridos localmente (de parentes, vizinhos, amigos), sem a intermediação de terceiros (associações e/ou cooperativas). 
Tabela 11 - Comportamento do cliente quanto aos mercados de insumos

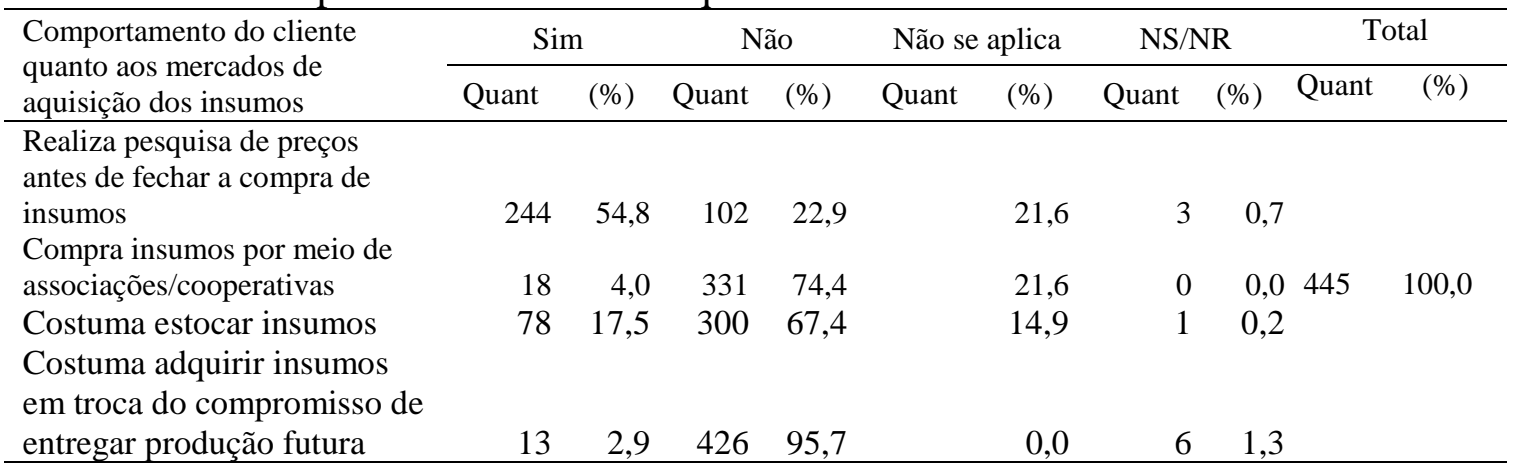

Fonte: BNB (2012).

Os dados sobre venda dos produtos corroboram as afirmações de Wilkinson (2002): ocorre preferencialmente no mercado local $(63,8 \%)$, dentro de uma rede de proximidade, nos denominados circuitos curtos. Outros destinos (centros vizinhos, outros estados, prefeitura etc) são adotados por somente 6,3\% dos entrevistados (BNB, 2012).

$\mathrm{Na}$ hora de vender os produtos, $51,9 \%$ dos entrevistados realizam pesquisa prévia de preços (Tabela 12) e, assim como no processo de aquisição de insumos, a maioria (64\%) pratica os mesmos preços que os vizinhos, sem se valer dos serviços de associações ou cooperativas (78\%), conforme BNB (2012). Portanto, a estratégia adotada para a compra de insumo se reproduz no ato da venda dos produtos, qual seja, preferência por mercados locais e contato direto com o consumidor. Dois aspectos principais são levados em conta pelos agricultores na sua decisão: os mercados locais os liberam das difíceis negociações requeridas no mercado formal, além de permitirem seguir a lógica de valorizar as relações de proximidade, reciprocidade e confiança que se engendram no processo de negociação de compra e venda.

Sobre a estocagem de produtos para venda em melhor ocasião, observa-se que a maior parte dos entrevistados $(68,3 \%)$ não costuma realizá-la (Tabela 12). Ou seja, os produtos são vendidos na medida em que aparecem compradores, predominando os circuitos curtos de comercialização. 
Tabela 12 - Comportamento do cliente quanto aos mercados de venda dos produtos

\begin{tabular}{|c|c|c|c|c|c|c|c|c|c|}
\hline \multirow{2}{*}{$\begin{array}{l}\text { Comportamento do cliente quanto } \\
\text { aos mercados de venda dos seus } \\
\text { produtos }\end{array}$} & \multicolumn{2}{|c|}{ Sim } & \multicolumn{2}{|c|}{ Não } & \multicolumn{2}{|c|}{$\begin{array}{l}\text { Não se } \\
\text { aplica }\end{array}$} & \multicolumn{2}{|c|}{ NS/NR } & Total \\
\hline & Quant & $(\%)$ & Quant & $(\%)$ & Quant & $(\%)$ & Quant & $(\%)$ & Quant (\%) \\
\hline $\begin{array}{l}\text { Realiza pesquisa de preços antes } \\
\text { de fechar a venda de seus } \\
\text { produtos }\end{array}$ & 231 & 51,9 & 128 & 28,8 & 83 & 18,7 & 3 & 0 & \\
\hline $\begin{array}{l}\text { Vende produtos por meio de } \\
\text { associacões/cooperativas }\end{array}$ & . & & & & 83 & & 0 & & 445100,0 \\
\hline Costu & 60 & 13,5 & & 68 & 81 & 18 & & - & \\
\hline Costuma vender produtos na folha & 12 & 2,7 & 352 & 79,1 & 81 & 18,2 & 0 & - & \\
\hline
\end{tabular}

Fonte: BNB (2012).

Uma característica importante dos circuitos curtos é o funcionamento do mercado em função da demanda e não da oferta, significando ser desnecessário concentrar a oferta de produtos em um único período, mas vender pequenas quantidades ao longo de um período determinado, à medida que aparecem compradores (WILKINSON, 2002). Portanto, para esses agricultores, conforme afirmaram 79,1\% dos entrevistados (Tabela 12), não é importante vender a produção "na folha", com a vantagem de se livrarem do compromisso com futura entrega a compradores determinados.

\section{CONSIDERAÇÕES FINAIS}

Entre os agricultores familiares brasileiros é possível identificar uma significativa diversidade de bases materiais e modos de produção, que definem diferentes estratégias para garantir a reprodução do grupo familiar. Em parte, isso resulta da diferenciação promovida pelo processo de desenvolvimento capitalista, que gera condições desiguais de acesso a bens materiais, a conhecimento e a tecnologias. É a interação dessas bases com o meio (socioeconômico e agroecológico) que determina as condições objetivas de produção desiguais dentro de uma sociedade capitalista.

Considerando a lei e a tipificação adotadas pelo governo brasileiro para identificar os agricultores familiares, a maior parcela enquadra-se no segmento Pronaf B e vive no semiárido. Esses agricultores são objeto de estudo no presente trabalho. Os dados empíricos que deram suporte à análise e aos resultados foram extraídos de uma base do BNB relativa a uma pesquisa de campo realizada em 2012 com clientes do Pronaf.

A análise dos dados permitiu concluir que os entrevistados estão distribuídos equitativamente entre os gêneros e residem principalmente na zona rural dos municípios. As 
condições de moradia são boas, pois a quase totalidade tem residência própria, acesso às redes públicas de energia elétrica e abastecimento de água, mas com deficiências em relação à água potável.

As condições dos meios de produção são graves, principalmente em relação ao acesso à terra, condição material fundamental para a produção que proporciona a segurança alimentar. Mesmo entre aqueles com áreas próprias, observa-se um tamanho médio extremamente reduzido para exploração em regiões semiáridas, em torno de 10 hectares. Mais grave ainda é a constatação de que boa parte dos agricultores sequer dispõe de terras próprias. Observou-se que a disponibilidade efetiva de áreas para exploração contribui para a definição dos tipos de máquinas, equipamentos e implementos e/ou tecnologias a utilizar na unidade familiar.

$\mathrm{O}$ acesso à orientação e a informações técnicas também é limitado entre os agricultores pesquisados, ressaltando-se a gravidade do problema em função da insuficiência de profissionais e estruturas inadequadas no sistema Ater. Isso repercute negativamente, tanto na adoção de práticas simples e de baixo custo no uso indiscriminado e sem proteção de determinados defensivos agrícolas que põem em risco a saúde humana e o meio ambiente.

A interação das condições materiais e conceituais dadas, com os meios social e agroecológico do semiárido, estimulam a elaboração e a prática de estratégias particulares. Para ampliar a área de produção, diversificam as atividades e realizam consórcio entre culturas, exploram áreas cedidas por terceiros, arrendadas ou em parceria. Para complementar a renda, praticam atividades não agropecuárias e ocupam espaço no mercado de trabalho local, fora da unidade familiar. Enfim, dentro e fora da unidade familiar as atividades revelam-se importantes no âmbito das estratégias dessas famílias, uma vez que são diversificadas e geram renda familiar, complementando-se e garantindo a sobrevivência e a reprodução do grupo.

As oportunidades de acesso ao crédito mostram-se importantes na definição de estratégias produtivas, de mercado e de reprodução familiar que os agricultores utilizam. A metodologia adotada para operacionalização do Pronaf B na área de atuação do BNB, denominada de Agroamigo, tem contribuído para a concretização das estratégias produtivas e inibição da inadimplência dos mais pobres, na medida em que adota o gerenciamento individualizado e leva em consideração as necessidades individuais do tomador do crédito. 
O financiamento de atividades não agropecuárias tem sido outra forma de suporte do Pronaf $\mathrm{B}$ às estratégias produtivas dos seus clientes. Além de refletir o reconhecimento dessa prática entre os agricultores familiares, incentiva o desenvolvimento de alternativas econômicas menos suscetíveis às intempéries climáticas que afetam o semiárido. Porém, tais alternativas ainda são submetidas a limitações. Especialmente nos casos mais bem-sucedidos, os ganhos com essas atividades ultrapassam a renda máxima para obtenção da DAP, sem, contudo, tornar o agricultor apto a enquadrar-se em grupos superiores do Pronaf. Essa limitação inibe a ampliação e até o desenvolvimento de determinadas atividades com maior demanda por matérias-primas. Isso tem ocorrido não apenas por questões relacionadas às exigências de renda mínima proveniente da atividade agropecuária, mas também devido às condições de acesso à terra e à infraestrutura, entre outros meios de produção agropecuária.

Outra condição imposta no Programa, e que merece discussão, diz respeito à limitação do crédito para custeio por contrato e à obrigatoriedade de sua vinculação ao investimento. Também este aspecto pode produzir repercussão negativa no desenvolvimento das atividades, particularmente nas não agropecuárias, em função da importância que assume o aporte de matérias-primas posteriormente aos investimentos em máquinas, equipamentos e utensílios.

$\mathrm{O}$ acesso aos mercados acontece de uma forma particular entre esses agricultores. A aquisição de insumos e a venda da produção própria ocorrem primordialmente nos mercados locais, sem a intermediação de organizações associativas, permitindo o contato direto entre vendedor e consumidor. Esse modo de comercialização dispensa os agricultores de lidarem com as regras do mercado formal, promove a aproximação entre o produtor e o cliente, estimulando relações de reciprocidade e vínculos de confiança, comuns em comunidades rurais nordestinas.

É importante entender que o argumento sobre a necessidade de gerar escala, tanto para a aquisição de insumos quanto para a comercialização da produção, tem pouco sentido quando se levam em conta aspectos como a racionalidade própria desse segmento de agricultores, a vulnerabilidade das condições materiais de produção, a deficiência hídrica e as características agroecológicas do semiárido brasileiro. Neste sentido, os resultados oferecem subsídios para fomentar a discussão acerca das dificuldades que os agricultores familiares têm de se envolver em ações coletivas. A constatação de que a maioria realiza a 
compra dos insumos e a venda dos produtos sem intermediação de uma associação ou cooperativa sugere que se revejam os argumentos da literatura sobre a importância de organização para este fim, pelo menos quando se está lidando com agricultores com o perfil aqui observado.

Ressalte-se, no entanto, as limitações do estudo original para a compreensão dos contextos sociocultural nos quais se inserem os clientes do Pronaf B e político/de poder em que as instituições proponentes e executoras atuam, em função da opção metodológica. Mais adequado seria adotar um método com abordagem processual, multidimensional e interdisciplinar. Isso permitiria entender o objeto de pesquisa sob diversos ângulos e olhares, pela combinação de elementos e abordagens de pesquisa qualitativa e quantitativa, admitindo, inclusive, a combinação de instrumentos de coleta diversos e não apenas os questionários semiestruturados.

A despeito das limitações de método, as análises aqui apresentadas indicam o quão problemática é a imposição de políticas e programas, muitas vezes opostos às necessidades e às expectativas dos agricultores. Sinalizam para os reais motivos de descontinuidade, inadimplência, abandono da atividade financiada e descrédito de algumas políticas públicas. Pressupõe-se, portanto, que um pré-requisito para elaboração e execução de políticas públicas é o conhecimento e a consideração das especificidades, dos potenciais e das limitações do seu público-alvo.

Por outro lado, são evidentes alguns avanços do Pronaf B nesse aspecto, destacandose a criação da metodologia do Agroamigo para a sua operacionalização. O sucesso do Agroamigo reside exatamente em aproximar o banco operador (BNB) dos potenciais clientes do Pronaf B, ampliar sua capacidade de financiar as atividades de um segmento historicamente excluído das políticas públicas de crédito e impor melhor qualidade ao modus operandi, embora isso não encerre os problemas de adequação do Pronaf B ao seu públicoalvo. As informações apontam para a necessidade de alguns ajustes que fogem da alçada daquela instituição, tais como mudanças nas regras atuais de exigência de renda mínima da agropecuária e nas normas que atrelam o custeio ao investimento e o limita a 35\% do valor total do contrato. Sinalizam, ainda, para a necessidade de a ação valorizar mais os mercados de proximidade e menos o grande mercado, pelo menos quando se tratar de clientes localizados em áreas mais remotas do semiárido nordestino. 
Além disso, os resultados indicam limitações que surgem em programas operados isoladamente. No caso particular do Pronaf B, o cumprimento pleno dos objetivos propostos esbarra na falta de políticas complementares (de responsabilidade do governo central, dos governos estaduais ou locais) ou das dificuldades de articulação com as já existentes. Enfim, contribuiria para a efetividade do Programa, a construção articulada de condições mínimas de infraestrutura de produção, de transporte e de comercialização.

Da mesma forma, as tecnologias existentes, adaptadas ou adaptáveis ao modo de produção desses agricultores, precisam, de alguma forma, chegar a eles. A Empresa Brasileira de Pesquisa Agropecuária (Embrapa) tem, em suas prateleiras, um variado estoque de tecnologias simples e de baixo custo que poderiam ser difundidas a partir de ações articuladas com os programas de crédito destinados a agricultores familiares. Mas ações nessa direção requerem um sistema de Ater com recursos, estrutura, pessoal e modelo de intervenção adequados à realidade desses agricultores.

Ações no sentido de ajustar rumos do sistema Ater no Semiárido requerem, sobretudo, o reconhecimento da inadequação do modelo para atendimento de agricultores familiares da região e disposição para assumir o compromisso de mudança dentro das próprias instituições, iniciando por avaliar as metodologias adotadas nas Aters.

\section{REFERÊNCIAS}

ABRAMOVAY, R. Alcance e limite das finanças de proximidade no combate no combate à inadimplência: o caso do Agroamigo. São Paulo: Fipe, 2008. (Texto para Discussão, n. 10).

ALVES, M. O. Conhecendo o público-alvo do Pronaf B: agricultores familiares descapitalizados ou em processo de descapitalização. Fortaleza, CE, 2005. Disponível em: <https://bit.ly/2ZhUY5V>. Acesso em: 4 out. 2017.

Mercado, arame e estado: recursos comuns e resistência em Lagoa dos Cavalos no sertão do Ceará. 341 fl. Brasília: Universidade de Brasília, 2012. Tese (Doutorado em Desenvolvimento Sustentável).

BNB - BANCO DO NORDESTE DO BRASIL. Concurso inovação na gestão pública federal: experiência Agroamigo. Fortaleza: BNB, 2010. Disponível em: <https://bit.ly/2PgLUto $>$. Acesso em: 6 out. 2017.

Banco de dados pesquisa Datamétrica. [CD-ROM]. Fortaleza: Banco do Nordeste do Brasil, 2012.

Agroamigo. Fortaleza: Banco do Nordeste do Brasil, 2015. Disponível em: <http://www.bnb.gov.br/web/guest/agroamigo $\rangle$. Acesso em: 29 jan. 2015. 
BRASIL. Ministério da Integração Nacional - MIN. Nova delimitação do Semiárido. Brasília: SUDENE, 2018. Disponível em: <http://sudene.gov.br/images/arquivos/semiarido/arquivos/Rela\%C3\%A7\%C3\%A3o_de_ Munic\%C3\%ADpios_Semi\%C3\%A1rido.pdf>. Acesso em: 10 ago. 2019.

CHAYANOV, A. V. La organización de la unidad econômica campesina. Buenos Aires: Ediciones Nueva Vision, 1974.

ECHEVERRI, R. Ruralidade, territorialidade e desenvolvimento sustentável. Brasília: IICA, 2005.

GAMA DA SILVA, P. C. G. et al. Caracterização do semiárido brasileiro: fatores naturais e humanos. In: SÁ, I. B.; GAMA DA SILVA, P. C. G. (Orgs.). Semiárido brasileiro: pesquisa, desenvolvimento e inovação. Petrolina: Embrapa Semiárido, 2010.

IBGE. Estimativas da População 2019. 2019. Disponível em: $<$ https://www.ibge.gov.br/estatisticas/sociais/populacao/9103-estimativas-depopulacao.html?=\&t=o-que-e>. Acesso em: 10 ago. 2020.

Censo Agropecuário 2006: tabulações especiais da agricultura familiar. Brasília: IBGE; MDA, 2012. Disponível em: <https://bit.ly/2DiZNme>. Acesso em: 6 abr. 2017.

LANDINI, F. P. Problemas enfrentados por extensionistas rurais brasileiros e sua relação com suas concepções de extensão rural. Revista Ciência Rural, Santa Maria, v. 45, n. 2, p. 371-377, 2015. Disponível em: 〈https://bit.ly/2UItPKz〉. Acesso em: 26 set. 2017.

SILVA NETO, B.; DEZEN, M.; SANTOS, P. dos. O conceito de reprodução social na análise de unidades de produção agropecuária. Teoria e Evidência Econômica, v. 15, n. 32, p. 87-108, jan./jun. 2009. Disponível em:

<http://seer.upf.br/index.php/rtee/article/view/4747/3181>. Acesso em: 12 ago. 2020.

VIEIRA, C. O feijão em cultivos consorciados. Viçosa: UFV, 1989.

WILKINSON, J. Sociologia econômica, a teoria das convenções e o fortalecimento dos mercados. Revista Ensaios (FEE), Porto Alegre, v. 23, n. 2, 2002. Disponível em: <https://bit.ly/2ZaoYAu $>$. Acesso em: 13 nov. 2011.

ZANI, F. B.; COSTA, F. L. Avaliação da implementação do Programa Nacional de Fortalecimento da Agricultura Familiar - novas perspectivas de análise. Revista de Administração Pública, Rio de Janeiro, v. 48, n. 4, p. 889-912, 2014. 